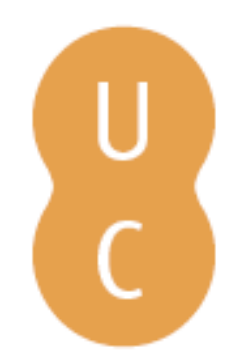

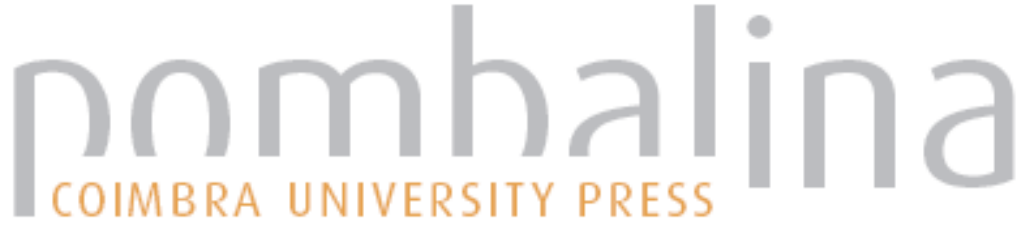

\section{O Programa Nacional de Vacinação e outras vacinas}
Autor(es):
Rodrigues, Fernanda
Publicado por: Imprensa da Universidade de Coimbra
URL
persistente: URI:http://hdl.handle.net/10316.2/43116
DOI: $\quad$ DOI:https://doi.org/10.14195/978-989-26-1300-0_15

Accessed : $\quad$ 26-Apr-2023 11:45:39

A navegação consulta e descarregamento dos títulos inseridos nas Bibliotecas Digitais UC Digitalis, UC Pombalina e UC Impactum, pressupõem a aceitação plena e sem reservas dos Termos e Condições de Uso destas Bibliotecas Digitais, disponíveis em https://digitalis.uc.pt/pt-pt/termos.

Conforme exposto nos referidos Termos e Condições de Uso, o descarregamento de títulos de acesso restrito requer uma licença válida de autorização devendo o utilizador aceder ao(s) documento(s) a partir de um endereço de IP da instituição detentora da supramencionada licença.

Ao utilizador é apenas permitido o descarregamento para uso pessoal, pelo que o emprego do(s) título(s) descarregado(s) para outro fim, designadamente comercial, carece de autorização do respetivo autor ou editor da obra.

Na medida em que todas as obras da UC Digitalis se encontram protegidas pelo Código do Direito de Autor e Direitos Conexos e demais legislação aplicável, toda a cópia, parcial ou total, deste documento, nos casos em que é legalmente admitida, deverá conter ou fazer-se acompanhar por este aviso.

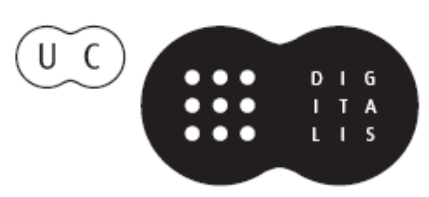


Capítulo 15.

O Programa Nacional de Vacinação e outras vacinas
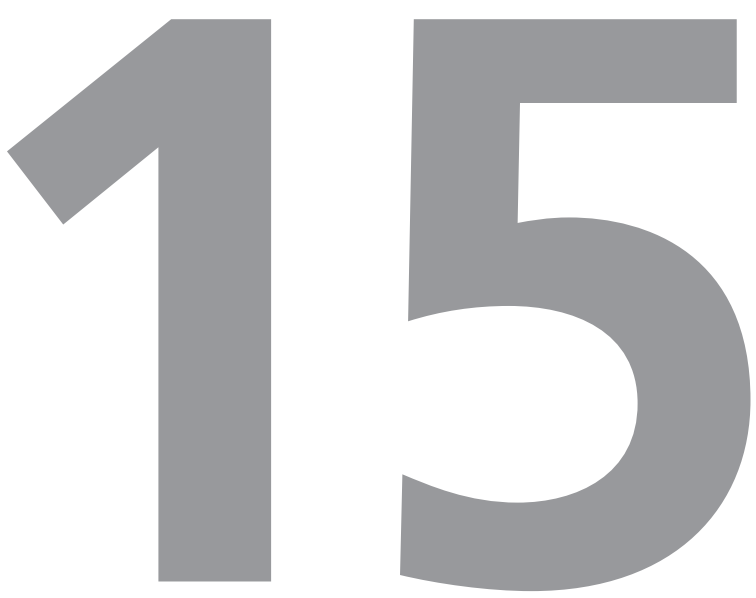

Fernanda Rodrigues 


\subsection{CONTEXTO}

Embora existam registos históricos que revelam tentativas anteriores de proceder a vacinação, é ao médico inglês Edward Jenner (1749-1823) que se atribui o mérito das bases científicas da mesma. Jenner investigou a crença popular de que os camponeses que lidavam com gado bovino com varíola e que tinham lesões semelhantes às bovinas, não contraiam varíola humana. Com base nesta observação, inoculou material de uma lesão de varíola bovina da mão de uma mulher no braço de um menino - James Phipps - que posteriormente foi exposto a varíola humana e não contraiu a doença. Além disso, Edward Jenner previu que, aplicando a experiência com James Phipps a toda a população, um dia seria possível erradicar esta doença. Tal viria a acontecer cerca de dois séculos depois, pela vacinação de grande número de indivíduos, associada a estratégias de vacinação dos contactos de casos.

Muitos avanços científicos se seguiram, existindo atualmente mais de 20 vacinas disponíveis. Foi erradicada uma doença, outras eliminadas e muitas controladas, sendo extraordinário o benefício da vacinação. Segundo a Organização Mundial de Saúde (OMS), em conjunto com a água potável, são as duas medidas com maior impacto em termos de saúde pública.

\subsection{DESCRIÇÃO DO TEMA}

\subsubsection{O Programa Nacional de Vacinação Português}

O Programa Nacional de Vacinação (PNV) português iniciou-se em 1965. Estudos epidemiológicos e serológicos então efetuados permitiram avaliar o impacto de doenças contra as quais havia vacinas disponíveis e foi criada uma comissão de técnicos que propunha vacinas, aspetos organizativos e funcionais. A rede de postos de vacinação foi baseada nos serviços existentes e foi criado o Boletim Individual de Vacinação.

Desde o seu início, é um programa universal (aplicável a todas as pessoas residentes em Portugal), não obrigatório, gratuito, gerido a nível nacional mas descentralizado, aplicado sobretudo na rede de serviços públicos, com um calendário recomendado e dinâmico, que pretende atingir elevadas coberturas vacinais, nas idades indicadas e sem assimetrias geográficas.

A primeira vacina do PNV foi a da poliomielite e outras foram sendo progressivamente incluídas (Quadro 1), contemplando atualmente 13.

A evolução do PNV envolveu a introdução de novas vacinas, determinada pela sua disponibilidade, por fatores epidemiológicos e de custo-benefício. A atualização dos esquemas implementados foi ocorrendo de acordo com a evolução epidemiológica e do conhecimento científico. O programa em vigor a partir de 2017 está apresentado no Quadro 2.

A introdução de algumas vacinas fez-se simultaneamente com campanhas. São exemplos a campanha contra a poliomielite, contra o sarampo e contra o meningococo $C$, de modo a imunizar rapidamente o maior número possível de pessoas e obter o controlo rápido da doença através da imunidade de grupo. A campanha mais recente foi contra o papiloma vírus humano (HPV) e pretendeu complementar a vacinação de rotina, protegendo um maior número de jovens. 


\begin{tabular}{|c|c|c|c|c|c|c|c|c|c|}
\hline & 1965 & 1974 & 1984 & 1987 & 1993 & 2000 & 2006 & 2008 & 2015 \\
\hline \multicolumn{10}{|c|}{ Varíola } \\
\hline \multicolumn{10}{|c|}{ Difteria } \\
\hline \multicolumn{10}{|c|}{ Tétano } \\
\hline \multicolumn{10}{|c|}{ Tosse convulsa } \\
\hline \multicolumn{10}{|c|}{ Tuberculose } \\
\hline \multicolumn{10}{|c|}{ Poliomielite } \\
\hline \multicolumn{10}{|c|}{ Sarampo } \\
\hline \multicolumn{10}{|c|}{ Rubéola } \\
\hline \multicolumn{10}{|c|}{ Parotidite epidémica } \\
\hline \multicolumn{10}{|c|}{ Hepatite B } \\
\hline \multicolumn{10}{|c|}{ Hib } \\
\hline \multicolumn{10}{|c|}{ MenC } \\
\hline \multicolumn{10}{|l|}{ HPV } \\
\hline Pn13 & & & & & & & & & \\
\hline
\end{tabular}

Hib - vacina contra Haemophilus influenzae tipo b; MenC - vacina conjugada contra Neisseria meningitidis grupo C; HPV - vacina contra Papiloma vírus humano; Pn13 - vacina conjugada peumocócica 13 valente.

Quadro 1. Introdução de novas vacinas no Programa Nacional de Vacinação Português.

\begin{tabular}{|c|c|c|c|c|c|c|c|c|c|}
\hline & Nascimento & $2 \mathrm{M}$ & $4 \mathrm{M}$ & $6 \mathrm{M}$ & $12 \mathrm{M}$ & $18 \mathrm{M}$ & $5 A$ & $10 \mathrm{~A}$ & $\begin{array}{l}25,45,65,> \\
65 A(10 / 10 A)\end{array}$ \\
\hline TB & \multicolumn{9}{|c|}{ Grupos de risco } \\
\hline VHB & VHB1 & VHB2 & & VHB3 & & & & & \\
\hline Hib & & Hib1 & Hib2 & Hib3 & & Hib4 & & & \\
\hline TDPa & & DTPa1 & DTPa2 & DTPa3 & & DTPa4 & DTPa5 & & \\
\hline VIP & & VIP1 & VIP2 & VIP3 & & VIP4 & VIP5 & & \\
\hline Pn13 & & & Pn13 1 & Pn13 2 & Pn13 3 & & & & \\
\hline MenC & & & & & MenC1 & & & & \\
\hline VASPR & & & & & VASPR1 & & VASPR2 & & \\
\hline HPV & & & & & & & & HPV1,2 & \\
\hline Td & & & & & & & & Td1 & $\mathrm{Td} 2,3,4,5, \ldots$ \\
\hline
\end{tabular}

TB - tuberculose; VHB - vacina contra vírus da hepatite B; Hib - vacina contra Haemophilus influenzae tipo b; TDPa - vacina contra difteria, tétano e tosse convulsa (acelular); para grávidas, uma dose em cada gravidez, administradas entre 20 a 36 semanas de gestação; VIP - vacina injetável contra a poliomielite; Pn13 - vacina conjugada peumocócica 13 valente; MenC - vacina conjugada contra Neisseria meningitidis grupo C; VASPR - vacina contra sarampo, papeira e rubéola; HPV - vacina contra Papiloma vírus humano; Td - vacina contra tétano e difteria

Quadro 2. Programa Nacional de Vacinação Português proposto para 2017. 
Também já ocorreram campanhas complementares de vacinação, como por exemplo contra o sarampo, de modo a eliminar bolsas de suscetíveis entretanto acumuladas que poderiam levar à ocorrência de surtos.

Algumas vacinas já eram administradas à população portuguesa antes da implementação do PNV, mas com taxas de cobertura muito inferiores. Após o seu início, obtiveram-se coberturas vacinais muito elevadas, das melhores do mundo. E assim foi possível erradicar a varíola, eliminar o sarampo e a poliomielite e conseguir uma redução drástica da morbilidade e mortalidade de várias outras doenças.

A aplicação informática SINUS módulo de vacinação permite toda a gestão do PNV, incluindo emissão de convocatórias e avaliação das coberturas vacinais.

A avaliação das metas do PNV faz-se através de:

- analise da cobertura vacinal;

- avaliação do estado imunitário da população com estudos serológicos para as doenças-alvo da vacinação;

- avaliação da efetividade das vacinas nas doenças-alvo da vacinação, pela da vigilância epidemiológica clínica e laboratorial e pelas Doenças de Declaração Obrigatória (DDO).

O PNV é submetido a uma avaliação anual interna regional e nacional, a uma avaliação externa internacional europeia - European Centre for Disease Prevention and Control (ECDC) e global (OMS).

O extraordinário sucesso do PNV português, que em 2015 completou 50 anos, é reconhecido a nível internacional.

\subsubsection{Princípios básicos da vacinação}

Com a vacinação pretende-se que a administração de um ou mais antigénios desencadeie a produção de anticorpos tal como aconteceria com a doença, com o mínimo possível de efeitos secundários, e que protegerão o individuo num contacto posterior com o agente infecioso. Pretende-se que estes anticorpos sejam funcionantes, atinjam níveis considerados protetores e que persistam pelo maior período de tempo possível. Ao longo dos anos foi-se percebendo que algumas vacinas atuavam também através de um outro mecanismo muito importante, designado por imunidade de grupo ou proteção indireta. Ao interferir na colonização prevenindo-a ou reduzindo a sua densidade no individuo vacinado, previnem ou reduzem a transmissão para os não vacinados que ficam assim menos expostos e não adquirem o microrganismo. Os não vacinados são protegidos indiretamente, beneficiando do contato com os vacinados. Para existir imunidade de grupo são necessárias coberturas vacinais muito elevadas. No caso do tétano, o microrganismo vive no solo e não coloniza o individuo pelo que a vacinação confere apenas proteção individual, não havendo imunidade de grupo. Só uma cobertura vacinal de 100\% evitaria o aparecimento de casos.

Em geral, os anticorpos produzidos pelos linfócitos B são considerados o mecanismo principal de proteção específica contra os antigénios vacinais. De uma forma resumida, os antigénios que fazem parte da vacina são reconhecidos por linfócitos B que se diferenciam em plasmócitos que produzem anticorpos e em células B de memória. Estas, aquando de um subsequente contacto 
com o mesmo antigénio (nova dose de vacina ou agente microbiológico), responderão rapidamente com produção de anticorpos. A primeira é designada resposta primária e a produção de anticorpos demora cerca de duas semanas; a segunda designa-se por memória imunológica e é muito mais rápida podendo a produção de anticorpos ocorrer em poucos dias.

A resposta imunológica à vacina é habitualmente avaliada através dos níveis de imunoglobulina $\mathrm{G}(\mathrm{IgG})$ sérica embora nem sempre haja correlação entre este valor e a proteção conferida. Esta resposta depende da idade, sendo menor e de curta duração no primeiro ano de vida. Sendo esta uma idade em que é mais elevado o risco de algumas doenças infeciosas, para algumas vacinas é necessário administrar várias doses no primeiro ano de vida, seguidas de dose (s) de reforço depois dos 12 meses.

Noutros casos, como por exemplo no sarampo, a vacinação não é feita no primeiro ano de vida pela possível interferência dos anticorpos maternos (adquiridos in útero e ainda presentes) na resposta imunológica da criança e a segunda dose serve para ultrapassar falências vacinais primárias que ocorrem em 5 a 10\% das crianças.

O desenvolvimento de uma vacina envolve estudos muito prolongados no tempo, com um componente laboratorial e depois em humanos. Este inclui quatro fases:

-fase 1: avaliação de segurança e doses; -fase 2: avaliação de segurança e imunogenicidade que mede o título de anticorpos produzidos;

-fase 3: avaliação de segurança e eficácia, isto é de que forma a vacina protege os indivíduos vacinados em relação à doença alvo. Estes estudos ocorrem em condições controladas, habitualmente antes do licenciamento da vacina;

-fase 4: avaliação de segurança e efetividade, isto é de que forma a vacina protege contra a doença alvo quando utilizada na vida real, fora de estudos com condições controladas. É influenciada pela cobertura vacinal e para algumas vacinas pela imunidade de grupo. A avaliação da segurança está presente em todas as fases e a sua monitorização permanecerá enquanto a vacina for utilizada.

Considera-se que houve erradicação de uma doença quando ocorreu interrupção da sua transmissão a nível mundial, na presença de um bom sistema de vigilância epidemiológica. Até hoje foi conseguida apenas a erradicação da varíola.

A eliminação de uma doença infeciosa é definida pela ausência de casos endémicos num determinado país ou área geográfica por um período mínimo de 12 meses, na presença de um bom sistema de vigilância epidemiológica. Só pode ser declarada pela OMS após a ausência de casos endémicos no país ou nessa área geográfica por um período de pelo menos 36 meses. Considera-se transmissão endémica a transmissão contínua (de agente microbiológico indígena ou importado) num determinado país ou área geográfica durante um período igual ou superior a 12 meses.

O sarampo é uma doença com possibilidade de eliminação porque existe uma vacina efetiva e segura e tem transmissão exclusivamente inter-humana. Na Europa, a OMS definiu o ano de 2007 como meta para a sua eliminação mas 
esta data foi sendo sucessivamente alterada e a situação epidemiológica agravou-se nos últimos anos, ocorrendo surtos na maioria dos 29 países europeus sob vigilância, incluindo Portugal.

Os programas de vacinação conduziram a uma dramática redução da incidência da poliomielite, tendo a OMS declarado interrupção da sua transmissão em várias áreas do mundo. No entanto, em 2014, ainda existiam três países (Afeganistão, Nigéria e Paquistão) endémicos para esta doença.

O desaparecimento de alguns tipos de microrganismos pela vacinação pode levar à sua substituição por outros tipos designando-se por

\section{fenómeno de substituição.}

A redução das taxas de cobertura vacinal pode levar ao ressurgimento de doenças controladas ou eliminadas tal como aconteceu recentemente com o sarampo em vários países do mundo.

\subsubsection{Tipos de vacinas, locais anatómicos e vias de administração}

As vacinas podem ser vivas atenuadas ou inativadas (Quadro 3). As vacinas vivas estão geralmente contraindicadas na gravidez, sendo as inativadas consideradas seguras para o feto. Em algumas circunstâncias de alterações imunitárias, as vacinas vivas estão contra-indicadas devido ao risco de doença provocada pelas estirpes vacinais. A vacinação destes doentes deve sempre ser decidida e efetuada sob orientação do médico assistente e de especialista com formação em infecciologia pediátrica.

Além do(s) antigénio(s), as vacinas têm na sua composição adjuvantes (i.e. alumínio) que aumentam a resposta imunológica, conservantes (i.e. tiomersal), antibióticos, estabilizadores (i.e. gelatina), emulsionantes e resíduos (i.e. proteínas de ovo).

As vias de administração podem ser injetável (subcutânea, intradérmica ou intramuscular) ou mucosa (oral ou nasal) (Quadro 3).

\begin{tabular}{|l|l|l|}
\hline Tipo de vacinas /Via de administração & Vivas atenuadas & Inativadas (IM) \\
\hline Injetável & VASPR (SC) & DTP, VIP, VHB , HPV \\
& Varicela (IM/SC) & Hib, MenC e Pn \\
TB (ID) & - conjugadas \\
\hline Mucosa & Rotavírus (oral) & \\
\hline
\end{tabular}

ID - intradérmica; SC - subcutânea; IM - intramuscular; VASPR - vacina contra sarampo, papeira e rubéola; TB - tuberculose; DTPa - vacina contra difteria, tétano e tosse convulsa (acelular); VIP - vacina injetável contra a poliomielite; VHB - vacina contra vírus da hepatite B; HPV - vacina contra Papiloma vírus humano; Hib - vacina contra Haemophilus influenzae tipo b; MenC - vacina conjugada contra Neisseria meningitidis grupo C; Pn13 - vacina conjugada peumocócica 13 valente

Quadro 3. Tipo e via de administração das vacinas 
Antes dos 12 meses são administradas na coxa pela quantidade de massa muscular, sendo exceção a vacina BCG que é administrada na parte superior do braço esquerdo. Não são dadas na nádega pelo risco de lesão do nervo ciático. Existem locais anatómicos definidos para cada vacina para promover boas práticas e facilitar a vigilância farmacológica de efeitos secundários.

É possível administrar em simultâneo mais do que uma vacina no mesmo membro, em locais distantes entre si em 2,5 a $5 \mathrm{~cm}$.

\subsubsection{Intervalo entre doses da mesma vaci-} na e entre vacinas diferentes

A maior parte das vacinas requer a administração de várias doses para conferir uma proteção adequada.

Intervalos superiores ao recomendado não reduzem a concentração final de anticorpos protetores pelo que, requerem apenas que se complete o esquema recomendado, independentemente do tempo decorrido desde a administração da última dose.

Intervalos inferiores aos mínimos aconseIhados podem diminuir a resposta imunológica e estas doses não devem ser consideradas válidas. Por razões epidemiológicas ou clínicas pode ser necessário encurtar os intervalos entre doses devendo nestes casos respeitar-se os intervalos mínimos aconselhados entre elas.

Excecionalmente, para situações de elevado risco, os esquemas aconselhados podem ter que ser alterados.

Como princípio geral, as vacinas inativadas não interferem com a resposta imunológica a outras vacinas podendo ser administradas simultaneamente, antes ou depois de outra vacina inativada ou viva.

Pelo contrário, a resposta imunológica a uma vacina viva injetável pode ficar comprometida se for administrada com um intervalo inferior a quatro semanas após outra vacina viva injetável. A administração de duas ou mais vacinas vivas injetáveis deve então ser feita no mesmo dia ou com um intervalo de pelo menos quatro semanas.

\subsubsection{Contraindicações à vacinação}

As contra-indicações verdadeiras às vacinas são raras e incluem reação anafilática prévia e administração de vacinas vivas à grávida e em algumas circunstâncias de alterações imunitárias. Há situações em que são necessárias precauções, exigindo prescrição médica e nas quais se incluem a doença aguda grave e hipersensibilidade não grave a dose anterior. A lista das falsas contra-indicações é extensa, incluindo doença ligeira aguda com ou sem febre, reações locais ligeiras a moderadas prévias, tratamento antibiótico concomitante, história pessoal de alergias e história anterior de convulsão febril.

\subsubsection{Reações adversas}

Tal como na administração de qualquer medicamento, as vacinas podem provocar reações adversas, excecionalmente graves (reações anafilácticas) e com mais frequência causam reações locais ligeiras tais como dor, eritema e edema. A febre é a reação sistémica mais frequente surgindo e desaparecendo habitualmente nas primeiras 24 a 48 horas após vacinação. Após a administração da VASPR, uma vacina viva, a febre surge entre 
o quinto e o décimo segundo dias, durando um a cinco dias.

As reações adversas possivelmente relacionadas com a administração de uma vacina devem ser sempre declaradas ao INFARMED pelos profissionais de saúde através do preenchimento de formulário próprio.

\subsubsection{Particularidades de algumas vacinas}

\section{Tuberculose:}

A vacina BCG faz parte do PNV desde 1965 e está indicada na prevenção de formas graves de tuberculose na criança, não prevenindo a evolução para doença pulmonar ativa.

Em Portugal foi-se assistindo a redução mantida da incidência da tuberculose, e em 2014 foi atingido o valor limite de baixa incidência definido pela OMS (20 casos/100.000 habitantes). Assim, em 2016 passaram a ser vacinadas apenas as crianças pertencentes a grupos de risco para a tuberculose.

\section{Poliomielite:}

A incidência de poliomielite baixou drasticamente em Portugal e no mundo na sequência da vacinação. Em Portugal não se verificam casos de poliomielite aguda por vírus selvagem desde 1987, estando a doença oficialmente eliminada desde 2002.

No entanto, se existirem bolsas de população com baixas taxas de cobertura vacinal e portanto suscetíveis, a doença pode reemergir sob a forma de surto ou epidemia.

\section{Difteria:}

O último caso em Portugal foi declarado em 1986.
Tétano:

Os resultados dependem única e exclusivamente da vacinação de cada pessoa. Em Portugal houve uma descida progressiva a partir dos anos 70, e o último caso de tétano neonatal ocorreu em 1997. Desde 2010 que os poucos casos de tétano surgem em idades mais tardias o que está de acordo com os dados serológicos que demonstram quase $100 \%$ de proteção nas coortes que foram abrangidas pelo PNV.

\section{Tosse convulsa:}

Vários países assistiram a um ressurgimento da tosse convulsa nos últimos anos. Poderão ser várias as razões para tal, parecendo que uma das mais importantes será a menor duração da imunidade induzida pela vacina acelular quando comparada com a vacina de célula inteira ou com a doença. Passou também a haver um maior reconhecimento da doença, o diagnóstico é mais fácil e acessível através da utilização de técnicas de biologia molecular (PCR) e apareceram estirpes com variações antigénicas constituindo escapes vacinais. São várias as estratégias possíveis para reduzir este problema embora com dificuldades de implementação e parecendo ser apenas soluções parciais. Estas incluem a vacinação do adolescente, a vacinação de familiares e contatos próximos do recém-nascido (cocoon), a vacinação dos profissionais de saúde em particular dos que têm contacto direto com grávidas e lactentes. Mas, até agora, a medida que mostrou maior benefício no controlo da doença no recém-nascido e pequeno lactente, grupo etário em que as manifestações clínicas são mais graves, é a vacinação da grávida. A vacina a administrar depois dos 4-5 anos de idade é a vacina Tdp, com menor dose antigénica. 
Hib:

Após introdução da vacina houve uma redução muito importante da doença invasiva (meningite, sépsis, bacteriémia, epiglotite, entre outras) causada pelo Haemophilus influenzae tipo b. No entanto, a doença não desapareceu e na vigilância nacional de doença invasiva por esta bactéria, embora a maioria dos casos identificados seja por Haemophilus influenzae não tipáveis, têm ocorrido cerca de 2 casos/ano causados por Haemophilus influenzae tipo b.

$\mathrm{Pn}:$

Estão comercializadas duas vacinas conjugadas antipneumocócicas, com 10 e 13 serotipos, sendo a última a utilizada em Portugal. Existem mais de 90 serotipos de pneumococo embora a maioria dos casos de doença seja causada por um grupo mais limitado, que inclui os contidos nas vacinas. Com a utilização da vacina houve uma diminuição muito importante da doença invasiva causada pelos serotipos vacinais, uma redução da frequência da otite média aguda e da pneumonia não bacteriémica. Os efeitos indiretos desta vacina na população não vacinada são muito importantes, tendo-se observado uma redução da doença por serotipos vacinais nos grupos etários não vacinados (imunidade de grupo). Ocorreu alguma substituição, com aumento de serotipos não vacinais mas este aumento foi inferior à redução que se obteve com os serotipos vacinais.

\section{MenC:}

Após a introdução desta vacina conjugada houve rápida redução da doença invasiva causada pelo grupo $C$ e não se observou aumento dos outros tipos. Além do efeito direto demostrou-se que os benefícios desta vacina se devem em grande parte à imunidade de grupo que produz.

Há algumas vacinas licenciadas e comercializadas em Portugal mas que não estão incluídas no PNV:

MenB:

Após redução importante da doença invasiva meningocócica causada pelo grupo C, a maioria dos casos de doença invasiva em Portugal passou a ser causada pelo grupo B, que atinge sobretudo crianças de baixa idade, em particular no primeiro ano de vida. Desde 2014 está comercializada uma vacina proteica de quatro componentes antigénicos, que protege contra estirpes que tenham pelo menos um desses antigénios. A proteção estimada para a Europa é de 78\%. O Reino Unido introduziu esta vacina no seu PNV em 2015 e vários países têm recomendações para a sua utilização.

\section{Men ACWY:}

Em alguns países têm-se assistido a um aumento dos casos de doença pelo grupos $\mathrm{Y}$ e W. No Reino Unido houve um aumento importante do último desde 2012, o que levou à introdução de uma dose da vacina conjugada contra os grupos A, C, W, e Y na adolescência, procurando obter proteção direta dos vacinados e redução da colonização deste grupo etário, que é o que apresenta maior taxa de colonização, e assim proteger de forma indireta as crianças mais pequenas.

\section{Rotavírus:}

É um dos agentes mais frequentes de gastroenterite aguda nos primeiros anos de vida e a quase totalidade das crianças terá pelo menos um episódio até aos 5 anos de idade, sendo 
mais frequente entre os seis e os 24 meses. Há duas vacinas disponíveis desde 2006, que podem ser administradas a partir das seis semanas de vida e devendo os esquemas estar completos às 24 (Rotarix $®$ ) e 32 semanas (Rotateq $\left.{ }^{\circledR}\right)$. Estão incluídas em programas de vacinação universal em mais de 80 países e a experiência da sua utilização demonstrou uma diminuição muito importante dos internamentos e observações por gastroenterite aguda por rotavírus. Esta redução também se verificou em grupos não vacinados, parecendo sugerir um efeito de imunidade de grupo. A monitorização da utilização das duas vacinas demonstrou para ambas um pequeno aumento do risco de invaginação intestinal, que parece ser menor quando a vacinação é feita mais cedo.

\section{Varicela:}

É uma doença altamente contagiosa, predominando na infância. Os adolescentes são mais suscetíveis a formas graves de doença. Há duas vacinas comercializadas, para serem administradas depois dos 12 meses, em duas doses. A sua utilização demonstrou elevada efetividade, não se acompanhando de aumento de zoster. No entanto, com base em resultados de modelos matemáticos, a OMS alerta para o risco de coberturas vacinais baixas (inferiores a 80\%) reduzirem a infeção na infância mas poderem desviá-la para grupos etários mais velhos, com maior risco de complicações.

\section{Gripe:}

O vírus influenza pode causar infeção em qualquer grupo etário, mas com taxas de incidência mais elevadas em crianças. A maior taxa de hospitalização e de complicações ocorre nos lactentes abaixo dos seis meses e nas crianças com patologia crónica. Em Portugal estão disponíveis vacinas trivalentes inativadas que incluem na sua composição dois subtipos de vírus influenza A e um tipo de influenza B. A OMS monitoriza continuamente a infeção pelo vírus da gripe e faz recomendações anuais sobre os tipos de vírus que devem ser incluídos na vacina em cada época. A vacinação contra a gripe é recomendada pela Direção Geral da Saúde (DGS) para grupos de risco nos quais a gripe pode ser particularmente grave, nomeadamente nas crianças com mais de seis meses e adolescentes com as seguintes patologias: doenças crónicas cardiovasculares, pulmonares, renais, hepáticas, hematológicas (hemoglobinopatias), metabólicas, neurológicas; imunodepressão primária, secundária a doença (infeção VIH, asplenia ou disfunção esplénica) ou secundária a terapêutica; terapêutica prolongada com salicilatos; diabetes mellitus; doença neuromuscular ou esquelética com compromisso da função respiratória; transplantação de órgãos sólidos ou medula óssea; adolescentes grávidas, que em outubro estejam no segundo ou terceiro trimestre da gravidez; obesidade mórbida; contactos próximos de grupos de risco; residentes ou internados por períodos prolongados em instituições prestadoras de cuidados de saúde.

\section{Hepatite A:}

Portugal é considerado um país de baixa endemicidade para esta doença, estando a vacina indicada em crianças e adolescentes que viajem para países com endemicidade intermédia ou alta, com patologia hepática crónica, candidatos a transplante de órgão, infetados por VIH, hemofílicos ou a receber hemoderivados ou que pertençam a comunidade onde seja detetado um surto. 
HPV para rapazes:

A vacina contra o HPV também pode ser administrada a rapazes. Estes beneficiam da imunidade de grupo se a cobertura vacinal nas raparigas for muito elevada. No entanto há muitos países com coberturas baixas ou que não utilizam a vacina e os homens que têm sexo com homens não beneficiam de forma significativa da vacinação do sexo feminino. A carga da doença por HPV no homem é relevante, nomeadamente para os condilomas genitais e não há rastreios implementados de cancros associados ao HPV.

\subsubsection{Vacinação da grávida}

Algumas doenças preveníveis pela vacinação apresentam maior morbilidade e mortalidade na grávida e podem associar-se a aborto espontâneo, anomalias congénitas, prematuridade e baixo peso ao nascer.

A vacinação da grávida permite proteger a mulher prevenindo a doença durante a gravidez e permite proteger o feto, o recém-nascido e - lactente por transferência de IgG através da placenta e transferência de $\lg \mathrm{A}$ através do leite materno. A prevenção da doença na mãe leva também a menor exposição do recém-nascido à infeção, protegendo-o dessa forma.

Os programas de imunização da grávida contra o tétano materno e neonatal começaram na década de 80 em países em desenvolvimento e mostraram ser seguros e muito efetivos na prevenção da doença na mãe e no recém-nascido.

As mulheres grávidas com infeção pelo vírus influenza apresentam maior risco de doença grave e o feto também pode ser afetado. A vacina da gripe está licenciada para utilização apenas depois dos seis meses de idade. Estas razões levaram à recomendação da vacinação da mulher grávida em vários países e a sua utilização mostrou que é segura e efetiva para a proteção da mãe, do feto, do recém-nascido e do pequeno lactente.

A reemergência da infeção por Bordetella pertussis nos últimos anos, com quadros graves e com mortalidade no recém-nascido e pequeno lactente, levou vários países, entre os quais se encontra Portugal a recomendar a vacina acelular contra a tosse convulsa durante cada gestação, entre as 20 e as 36 semanas, idealmente até às 32 semanas. Os resultados demonstraram a sua segurança e elevada efetividade na prevenção da doença naqueles grupos etários. Neste caso, a principal razão para a vacinação da grávida é a proteção da criança e não da mãe.

Vacinas contra Streptoccocus do grupo B e vírus sincicial respiratório estão atualmente a ser desenvolvidas para uso na gravidez.

\subsubsection{Desafios}

A eliminação e controlo de doenças leva ao esquecimento e desvalorização das mesmas, o que, associado a mitos poderá levar a uma menor adesão à vacinação, com o risco de ressurgimento de doenças já controladas ou eliminadas.

\subsection{FACTOS A RETER}

A vacinação resultou em extraordinários ganhos em saúde, com erradicação, eliminação e controlo de várias doenças infeciosas.

Mas, só é possível erradicar, eliminar e controlar as doenças infeciosas preveníveis pela 
vacinação se forem atingidas elevadas taxas de vacinação.

Existe risco de reemergência se as coberturas vacinais entretanto alcançadas não forem mantidas ou não se distribuírem homogeneamente na população (bolsas de suscetíveis).

O PNV é o programa mais antigo, mais universal, e bem-sucedido dos programas de saúde portugueses.

O empenho dos profissionais de saúde no cumprimento do PNV é indispensável para o seu sucesso.

\section{Leitura complementar}

DGS - Programa Nacional de Vacinação 2017

https://www.dgs.pt/em-destaque/novo-programa-nacional-de-vacinacao2.aspx

Green Book - immunisations against infectuious diseases https://www.gov.uk/government/collections/immunisationagainst-infectious-disease-the-green-book

Recomendações sobre vacinas extra Programa Nacional de Vacinação

http://www.spp.pt/UserFiles/file/Comissao_de_Vacinas/ Recomendacoes\%20sobre\%20vacinas\%20 extra\%20 PNV\%202015-2016.pdf

Kimberlin DW, Brady MT, Jackson MA, Long SS, eds. Red Book: 2015 Report of the Committee on Infectious Diseases. 30th ed. Elk Grove Village, IL: American Academy of Pediatrics, 2015.

DGS - Programa Nacional de Vacinação 2012

https://www.dgs.pt/ficheiros-de-upload-3/pnv2012-booklet. aspx

Vacinação em circunstâncias especiais http://www.spp.pt/UserFiles/file/Comissao_de_Vacinas/ Vacinacao_Circunstancias_Especiais.pdf 